\title{
The impact of pharmaceutical rebates on patients' drug expenditures
}

\author{
K. Ally Memedovich BHSc, Braden Manns MD MSc, Reed Beall PhD, Aidan Hollis PhD, Fiona Clement PhD
}

Cite as: CMAJ 2019 March 18;191:E308-12. doi: 10.1503/cmaj.181041

M ost pharmaceutical expenditure in Canada is private. In 2017, Canadian provincial, territorial and federal governments were reported to have spent $\$ 14.5$ billion on pharmaceuticals, accounting for only $43 \%$ of total pharmaceutical expenditure. ${ }^{1} \mathrm{~A}$ combination of private insurance and patient expenditures in the form of direct payment for pharmaceuticals, deductibles and other forms of co-insurance payments among those privately or publicly insured makes up the remaining $57 \%{ }^{2}$ Whereas much of the conversation around increasing pharmaceutical costs has focused on the substantial growth within public budgets, little attention has been paid to how the various approaches to pricing negotiation may affect patients. We discuss the complicated landscape of drug pricing in Canada and highlight the variable impact on patients' drug expenditures of the 2 most common practices within pharmaceutical pricing, confidential pricing and rebates, to help inform policy decisions.

\section{What does the pharmaceutical pricing landscape look like in Canada?}

Prescription drugs are not included in the Canada Health Act. ${ }^{3}$ As a result, each province and territory has developed its own publicly funded prescription insurance plans, described as a Canadian "patchwork" of plans. ${ }^{4}$ Historically, this has led to individual markets for pharmaceuticals, with each province negotiating individually with pharmaceutical manufacturers. Within the last 15 years, several pan-provincial processes (e.g., the Common Drug Review and the pan-Canadian Pharmaceutical Alliance) have emerged to create a cross-provincial approach.

Drug pricing is complex and involves multiple agencies. First, Health Canada issues a Notice of Compliance, indicating pharmaceuticals can be sold in Canada. This process assesses the safety and efficacy of a pharmaceutical, as well as information such as the labelling of the product; notably, pricing is not assessed. ${ }^{5}$ The Common Drug Review, supported by the Canadian Agency for Drugs and Technologies in Health (CADTH), then reviews pharmaceuticals for consideration of inclusion within the publicly funded insurance plans. The Common Drug Review evaluates the clinical- and cost-effectiveness of a pharmaceutical, and provides 1 of 3 recommendations to the publicly funded drug plans: 1) the pharmaceutical should be reimbursed, 2) the

\section{KEY POINTS}

- The drug-pricing landscape in Canada is complex, with 4 different agencies and each provincial, territorial and federal drug plan involved.

- Rebates, which are a form of price negotiation between the government and pharmaceutical manufacturers, commonly involve the government and patient paying the list price at the point of dispensation, with the rebate returning to the government's general revenue as a lump-sum payment within a specified time frame.

- The cost to patients when price negotiations are done through rebates (rather than from a transparent reduction in the list price) could be higher than the actual cost of the drug, depending on the patient's income, the drugs insured and the plan structure.

- Publicly funded insurance plans with a co-insurance payment structure with a low maximum out-of-pocket limit, such as in Alberta, or a fixed copayment structure, such as in the seniors' plans in Ontario, Newfoundland and Labrador, Prince Edward Island and New Brunswick, insulate patients from the price differences after negotiations.

- When mapping the way forward with changes to the Patented Medicine Prices Review Board and the current work of the Advisory Council on the Implementation of National Pharmacare, attention to cost-sharing mechanisms within plan structures and tackling high list prices may be more fruitful than targeting the confidentiality of pricing agreements.

pharmaceutical should be reimbursed under certain clinical criteria and conditions, or 3 ) the pharmaceutical should not be reimbursed. ${ }^{6}$ Currently, the Common Drug Review does not have a function to negotiate on price, but it can recommend listing with an explicit statement about the price reduction that would be required for the drug to be attractive for the public drug plans.

The pan-Canadian Pharmaceutical Alliance was established in 2010 and is responsible for negotiating prices of selected new pharmaceuticals. The alliance, which includes all provinces and territories, as well as the federal plans, aims to conduct joint provincial and territorial negotiations for pharmaceuticals. The objective of the alliance is to improve the consistency of pharmaceutical listings nationally, negotiate a lower price to ensure that benefits are cost-effective, and increase access to pharmaceuticals, 
primarily by using the combined purchasing power of the publicly funded plans involved. The tools available to the pharmaceutical alliance include, but are not limited to, transparent pricing reductions, confidential pricing reductions, rebate structures, volume discounts and maximum-expenditure agreements.

Alongside this process considering public reimbursement, the Patented Medicine Prices Review Board (PMPRB) determines the maximum average potential price (the "list price"), which is the highest price that can be charged for a patented pharmaceutical (to either public or private payers). ${ }^{7}$ The PMPRB's jurisdiction includes drugs protected by patents regarding active ingredients, manufacturing processes, delivery systems, dosage forms and indications for use. ${ }^{7}$ Further, according to subsection $85(1)$ of the Patent Act, prices do not need to be approved by the PMPRB before pharmaceuticals are sold in Canada; however, companies can consult the PMPRB to determine whether a price is excessive. ${ }^{7}$

Several factors are taken into account when deciding the list price and making a determination regarding whether a price would be considered excessive: the price of medications in the same therapeutic class, the current price of the medication and the amount being paid by other countries. ${ }^{7}$ Under current regulations, the Canadian price cannot be higher than the median price "paid" by 7 similar countries (France, Germany, Italy, Sweden, Switzerland, the United Kingdom and the United States). ${ }^{7}$ These countries were originally chosen because of similarities in the pharmaceutical industries between Canada and these countries. Note that these countries practise similar strategies of pricing negotiation as Canada, and thus the actual price remains unknown; ${ }^{8}$ the price paid is the publicly available price, which may be markedly higher than the negotiated confidential price including rebates, which can create confusion.

To address this concern, the 2017 Canadian federal budget included a modernization of the framework used by the PMPRB.
Five changes were proposed: introducing new factors to determine whether a pharmaceutical is excessively priced, amending the set of countries used for international comparison, adjusting the regulations for patentees of generic pharmaceuticals, updating the reporting requirements for all patentees and providing information related to third-party rebates. ${ }^{9}$ This last amendment would provide the PMPRB information regarding the actual price of a pharmaceutical rather than the list price, which would allow the PMPRB to further determine whether a pharmaceutical is priced excessively. ${ }^{9}$

\section{Who benefits from rebates?}

When a pharmaceutical is listed by a publicly funded insurance plan, a rebate may be negotiated between the government and the manufacturer of that pharmaceutical. A common model is that the government and patient, at the point of dispensation, pay the list price, with the rebate returning to the general government revenue as a lump-sum payment within a specified time frame. For example, consider a drug with a list price of $\$ 10$ and a $30 \%$ rebate within the context of a $30 \%$ patient-borne coinsurance. The government reports paying $\$ 7$ per unit, but receives a $\$ 3$ rebate per unit provided by the pharmaceutical company back into general government revenue, making the net price of the drug to the government $\$ 4$ (Figure 1). The patient, however, would still pay $\$ 3$ as a co-insurance payment, that is, $30 \%$ of the list price of $\$ 7$.

\section{How do rebates affect patients?}

We use 2 drug examples to illustrate the financial impact of rebates on patients. To identify the example drugs, we systematically searched for pharmaceuticals that met the following

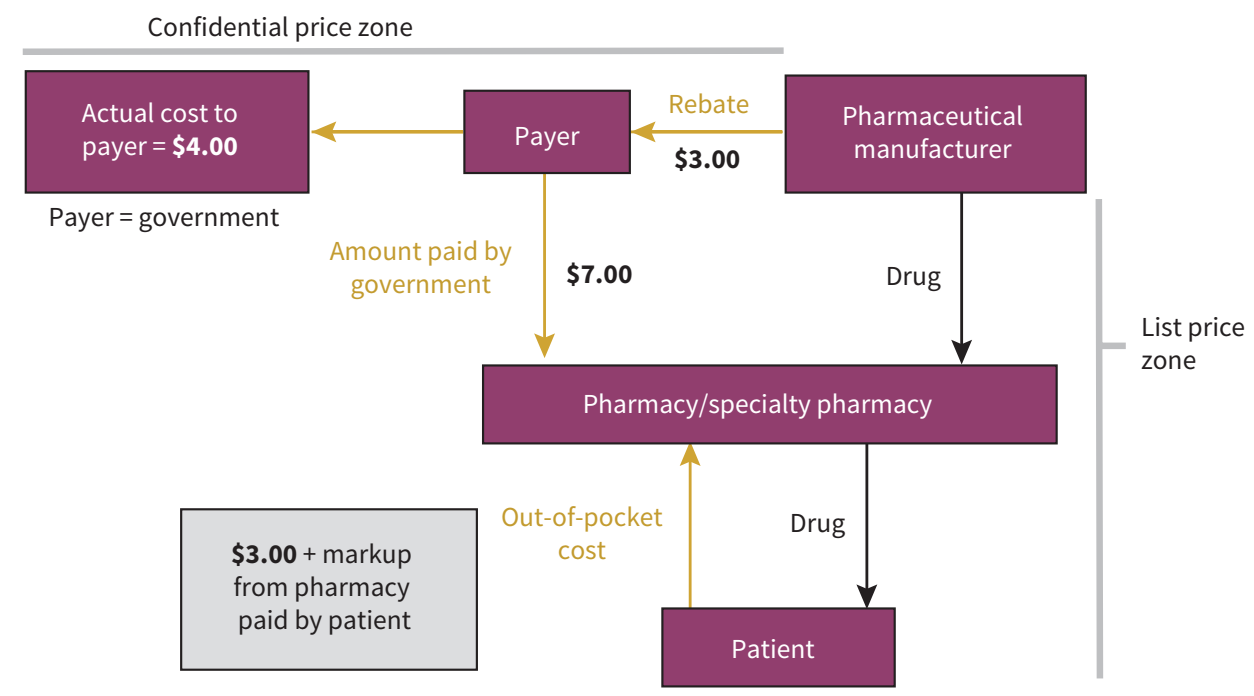

Figure 1: Impact of rebates on price. ${ }^{1}$ Assumes a $\$ 10$ list price, $30 \%$ rebate and $30 \%$ co-insurance. 
criteria: the Common Drug Review recommended inclusion within the publicly funded insurance plans, its documentation reported the list price (i.e., the price was not redacted), the price reduction required was noted in the recommendation, the recommended pharmaceutical was listed on the Alberta formulary, and the formulary list price was available (process flowchart presented in Appendix 1, available at www.cmaj.ca/lookup/suppl/ doi:10.1503/cmaj.181041/-/DC1). This process resulted in the selection of 2 pharmaceuticals: Jardiance (empagliflozin), a drug used in the management of type 2 diabetes, and Plegridy (pegylated interferon $\beta$-1a), a drug used to treat patients with relapsing-remitting multiple sclerosis.

British Columbia and Alberta were used as the example plan designs because their different plan structures and different patient cost-sharing arrangements broadly represent the differences seen nationally. British Columbia uses deductibles, whereas Alberta uses co-insurance with a maximum out-ofpocket limit per prescription. In Alberta, patients older than 65 years are responsible for $30 \%$ of the pharmaceutical costs per dispensing per prescription, with a maximum out-of-pocket expenditure of $\$ 25$ per prescription and the government paying the remaining expense. ${ }^{10}$ In British Columbia, patients (regardless of age) pay an annual deductible ranging up to $3 \%$ of net family income. After the deductible, patients are responsible for $30 \%$ of drug prices with a maximum out-of-pocket expenditure of $2 \%-4 \%$, depending on net family income. In this example, the annual median income ( $\$ 55600)$ for 2015 was used, resulting in a maximum annual out-of-pocket cost of $\$ 2275 . .^{11,12}$

\section{The example of Jardiance}

The list price of Jardiance is $\$ 2.62$ per day. However, the Common Drug Review suggested a $14 \%$ price reduction so that the price would be equal to the current least-costly treatment. ${ }^{13}$ Thus, the 3-month cost of Jardiance is calculated to be $\$ 235.80$ with a $14 \%$ assumed rebate, or $\$ 202.61$ if a $14 \%$ reduction in list price was achieved. In BC, patients would pay the total cost, irrespective of whether the price reduction was a list-price reduction or confidential price reduction; the total cost is less than the annual deductible. However, if a confidential price reduction was negotiated, the government would still receive the $\$ 33$ rebate. In Alberta, again regardless of a confidential or list-price reduction, the patient would pay the maximum $\$ 25$ copayment. However, with a rebate, the Alberta government would pay $\$ 210.80$ and receive a $\$ 33.01$ rebate, equating to a net cost of $\$ 177.79$, compared with a $14 \%$ list-price reduction, which would result in a government expenditure of $\$ 177.61 \mathrm{per}$ 3-month cycle (Figure 2A).

\section{The example of Plegridy}

Plegridy has a list price of $\$ 21584$ annually. To be cost-neutral, the Common Drug Review recommended price reductions of $4.6 \%, 16 \%$, and $24.6 \%$, depending on the comparator; $24.6 \%$ was chosen for this example. ${ }^{14}$ The cost of Plegridy is $\$ 21584$, or $\$ 16274$ with a $24.6 \%$ list-price reduction. In BC, patients would pay up to their maximum annual out-of-pocket expenditure (\$2275) in both cases. With a rebate, the government would pay a total of $\$ 19309$ and receive a $\$ 5310$ rebate, with a net expenditure of $\$ 13999$ (the same total expenditure achieved with a listprice reduction of $24.6 \%$ ). In both cases in Alberta, a patient would pay $\$ 25$. With a rebate, the government would pay $\$ 21559$ and receive a $\$ 5310$ rebate, with a net expenditure of $\$ 16249$ (the same as with a list-price reduction) (Figure 2B).

\section{Other examples}

These 2 examples do not, however, capture the breadth of the impact of rebates. Thus, we calculated the effect of various levels of rebates ranging from $10 \%$ to $90 \%$ on a range of list prices (from $\$ 25$ to $\$ 800$ per prescription), accounting for public drugplan rules across several provinces (Appendix 2, available at www.cmaj.ca/lookup/suppl/doi:10.1503/cmaj.181041/-/DC1). With a drug price of $\$ 25$ per prescription, if a $10 \%$ list-price reduction were achieved, a patient in Alberta would pay $\$ 6.75$ (30\% of $\$ 22.50)$, or $\$ 7.50$ if a $10 \%$ confidential rebate were used instead. In the BC model, the patient would pay $\$ 22.50$, or $\$ 25$ with the rebate. This equates to an $11 \%$ percent increase in patient expenditure per prescription dispensation. With a larger rebate (e.g., 50\%), an Alberta patient would pay $\$ 3.75$ (30\% of $\$ 12.50$ ) instead of $\$ 7.50$, and a patient in BC would pay $\$ 12.50$ instead of $\$ 25$ if a transparent list price were achieved (an increase of $100 \%$ in patient expenditure). The higher the drug price, the larger the increase is in patient expenditure within the BC model, whereas the Alberta patient is insulated after the drug price reaches $\$ 83$ per prescription.

We examine in Appendix 2 the increase in cost to a covered person if the insurer uses a confidential rebate instead of an equivalent reduction in the nominal price. Depending on the individual's income, the set of drugs insured and the plan structure, the additional cost could be higher than the actual cost of the drug. Although it is difficult to know how common this outcome is, because the size of rebates is confidential, it seems likely that there are insured individuals in some provinces who are actually paying - through copayments or deductibles much more than the true net price of their prescriptions.

\section{Is more transparency the way forward?}

As the examples presented show, rebates have a variable impact on patient drug expenditure. Within a co-insurance payment structure with a low maximum out-of-pocket limit, such as in Alberta, or a fixed copayment structure, such as in the seniors' plans in Ontario, Newfoundland and Labrador, Prince Edward Island and New Brunswick, ${ }^{15}$ patients are insulated from the price differences after negotiations. However, for pharmaceuticals with a low list price, patient expenditure is increased with the negotiation of confidential rebates. These increases may be small in absolute terms (e.g., an increase to $\$ 7.50$ from $\$ 6.75$ ), but relative increases may be large. Even small absolute increases may lead to cost-related nonadherence and financial hardship when patients are filling multiple prescriptions.

In a deductible structure, patients pay less for a given specific drug with a lower list price (compared with a high list price with a confidential rebate to the government). However, these decreases 


\section{A) Jardiance: $14 \%$ rebate}

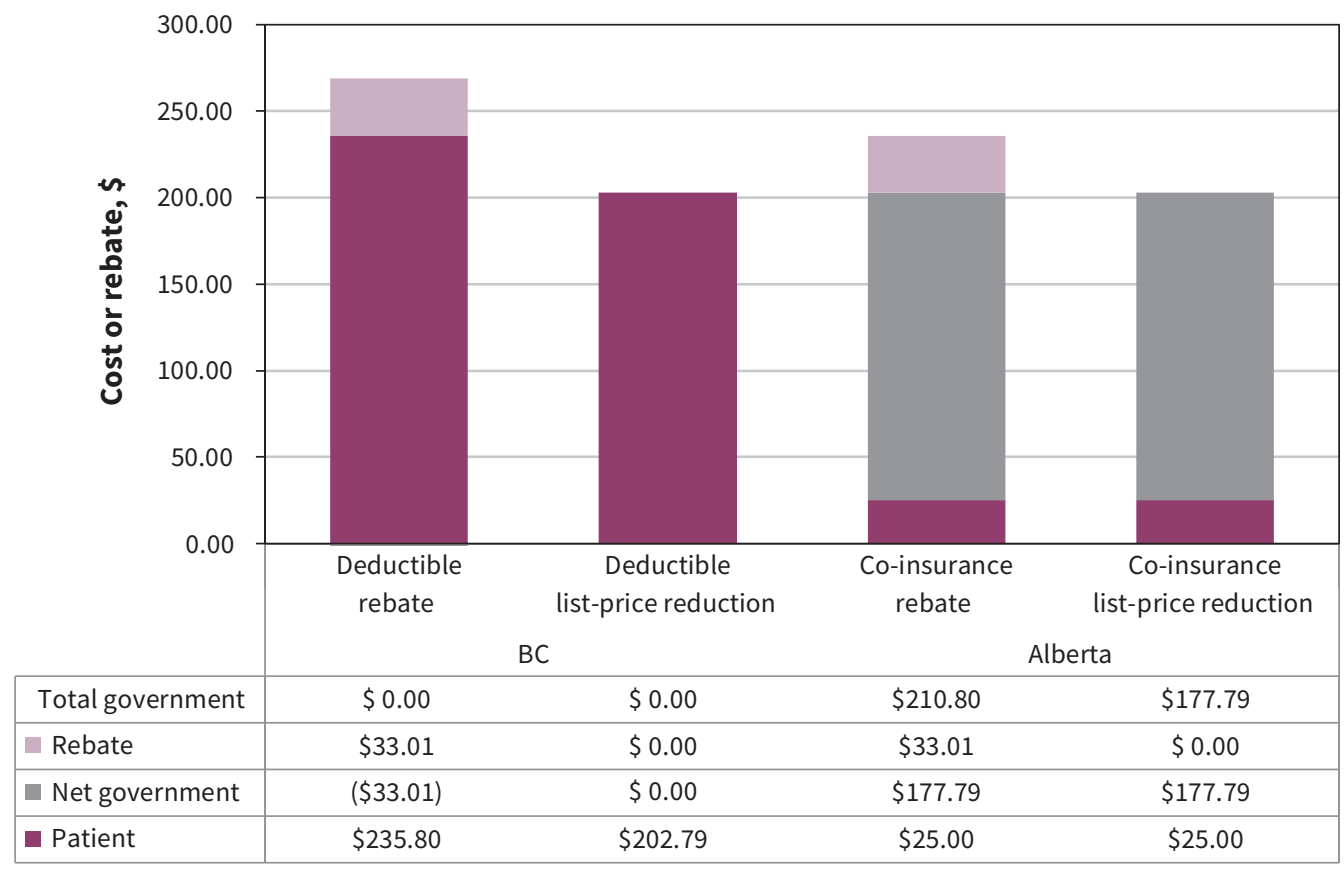

B) Plegridy: $24.6 \%$ rebate

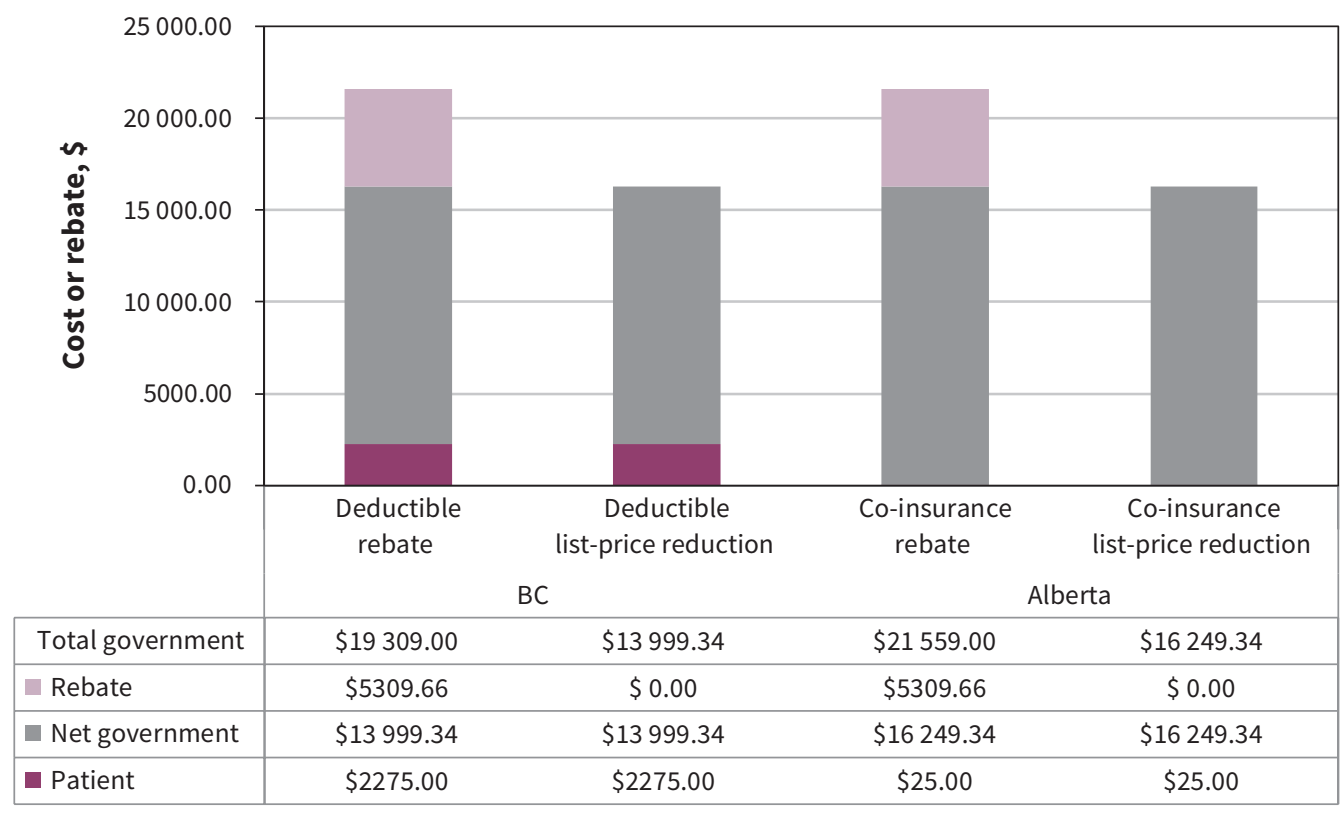

Figure 2: Effects of a rebate versus a list-price reduction in BC and Alberta for the example drugs (A) Jardiance and (B) Plegridy.

in patient expenditures must be balanced against the possibility that patients may reach their deductible limits more quickly with rebates, so the net impact on patients' total out-of-pocket expenditures remains unclear. Taken together, these findings highlight a disparity that currently exists across Canada because of different drug-plan structures. Within the current conversation about national pharmacare, we must pay attention to costsharing mechanisms and the interplay between pricing negotiation tools and approaches.

It is clear from the examples presented here that governments' expenditures will generally be reduced by using confidential expenditures in place of equivalent price reductions, given 
that copayments and deductibles depend on the nominal price. In some cases, with confidential rebates, governments can "earn" revenues from providing insurance with a deductible or copayment, because the patient pays more than the net price of the drug. This effectively amounts to an additional form of taxation on the patient at the point of prescription dispensation. However, the government may be able to negotiate lower net prices with confidential rebates than what would be possible if the demand of transparent price decreases were used, and confidential rebates offer a way of trading transparency for lower cost because pharmaceutical companies are generally reluctant to reveal a low price paid by any buyer. For example, circling back to one of the examples above, a $24.6 \%$ transparent list-price reduction for Jardiance seems more difficult to achieve than a $24.6 \%$ confidential price reduction using rebates.

Canada is simply one market in the global pricing approach. The use of rebates is common practice across many comparable jurisdictions, ${ }^{8}$ because all jurisdictions seek to obtain the lowest net price. However, the impact on patient expenditures has not been assessed except for in the context of US Medicare, in which a study reported that rebates were increasing the expenditures of Medicare as patients reached their deductible earlier. ${ }^{16}$

In the current context of changes to the PMPRB and the Advisory Council on the Implementation of National Pharmacare, there may be a policy window to make real change to prescription drug insurance in Canada. When mapping out the way forward, attention to cost-sharing mechanisms within plan structures and tackling high list prices may be more fruitful than targeting the confidentiality of pricing agreements.

\section{References}

1. Prescribed drug spending in Canada, 2017: a focus on public drug programs. Ottawa: Canadian Institute for Health Information; 2017.

2. National health expenditure trends. Ottawa: Canadian Institute for Health Information; 2017.

3. Canada Health Act. 1984, c. 6 , s. 1 .

4. Daw JR, Morgan SG. Stitching the gaps in the Canadian public drug coverage patchwork?: a review of provincial pharmacare policy changes from 2000 to 2010. Health Policy 2012;104:19-26.

5. How drugs are reviewed in Canada. Ottawa: Health Canada - Office of Submissions and Intellectual Property (OSIP); 2015.

6. Procedure for the CADTH Common Drug Review. Ottawa: Canadian Agency for Drugs and Technologies in Health; 2014.

7. Compendium of policies, guidelines and procedures. Ottawa: Patented Medicine Prices Review Board; 2017.

8. Morgan S, Daw J, Thomson P. International best practices for negotiating 'reimbursement contracts' with price rebates from pharmaceutical companies. Health Aff (Millwood) 2013;32:771-7.

9. Protecting Canadians from excessive drug prices: consulting on proposed amendments to the Patented Medicines Regulations. Ottawa: Health Canada; 2017.

10. Non-Group coverage benefit. Edmonton: Alberta Health. Available: www. health.alberta.ca/services/drugs-non-group.html (accessed 2018 Dec. 3).

11. Canadian Income Survey, 2014. Ottawa: Statistics Canada; 2016.

12. Fair PharmaCare Calculator. British Columbia Health. Available: www.health. gov.bc.ca/pharmacare/plani/calculator/calculator.html (accessed 2018 Dec. 3).

13. CADTH Canadian Drug Expert Committee final recommendation: empagliflozin (Jardiance - Boehringer Ingelheim [Canada] Ltd.). Common Drug Review 2016 Oct. 26.

14. CADTH Canadian Drug Expert Committee final recommendation: Pegylated Interferon-Beta 1A (Plegridy - Biogen Canada Inc.). Common Drug Review 2015 Dec. 17.

15. Campbell DJT, Manns Bj, Soril LJJ, et al. Comparison of Canadian public medication insurance plans and the impact on out-of-pocket costs. CMAJ Open 2017;5:E808-13.

16. Dusetzina SB. Conti RM, YU NL, et al. Association of prescription drug price rebates in Medicare Part $D$ with patient out-of-pocket and federal spending. JAMA Intern Med 2017;177:1185-8.
Competing interests: Braden Manns reports grants from Baxter Canada. Aidan Hollis reports personal fees from Apotex and Teva. No other competing interests were declared.

This article has been peer reviewed.

Affiliations: The Department of Community Health Sciences (Memedovich, Manns, Beall, Clement); O'Brien Institute for Public Health
(Memedovich, Manns, Beall, Hollis, Clement); the Department of Medicine (Manns); and the Department of Economics (Hollis), University of Calgary, Calgary, Alta.

Contributors: All of the authors designed the study. K. Ally Memedovich and Fiona Clement collected the data, which K. Ally Memedovich managed, and K. Ally Memedovich and Fiona Clement analyzed. All of the authors interpreted the data. K. Ally Memedovich and Fiona Clement prepared the manuscript, which all authors reviewed. All of the authors gave final approval of the version to be published and agreed to be accountable for all aspects of the work.

Correspondence to: Fiona Clement, fclement@ucalgary.ca 